\title{
Seismic response of aboveground steel storage tanks: comparative study of analyses by six and three corre- lated earthquake components
}

\section{Abstract}

Ground motions at a point on the ground surface can be decomposed to six components, namely three translational components and three rotational components; translational components include two components in the horizontal plane, and one in the vertical direction. Rotation about horizontal axes leads to rising of rocking, while the rotational component about a vertical axis generates torsional effects even in symmetrical buildings. Due to evident and significant contribution of ground shakings to the overall response of structures, rocking and torsional components of these motions resulted by strong earthquakes are recently subjected to widespread researches by engineering and research communities. In this study, first rotational components of ground motion are determined using a method developed by Hong-Nan $\mathrm{Li}$ and et al (2004). This method is based on frequency dependence on the angle of incidence and the wave velocity. In consequence, aboveground steel storage tanks (ASSTs) with different water elevations have been analyzed with the effects of these six components of earthquake. Three translational components of six important earthquakes have been adopted to generate relevant rotational components based on $S V$ and $S H$ wave incidence by the Fast Fourier Transform (FFT) with the discrete frequencies of time histories of translational motion. Using finite element method, linear properties of tank material including steel for cylindrical tanks have been taken into with considering fluid-structure interaction. Numerical linear dynamic analysis of these structures considering six components of earthquake motions is presented; results are compared with cases in which three translational components are considered.

\section{Keywords}

aboveground steel storage tanks; six components of earthquake motion; fluid-structure interaction
Taher Ghazvini ${ }^{\mathrm{a}}$, Hamid Reza Tavakoli ${ }^{*}$, Bahram Navayi Neya ${ }^{c}$, Leyla Kalani Sarokolayi ${ }^{d}$

${ }^{a}$ MSc Student - Department of Civil Engineering, Babol University of technology, Babol, Iran.

${ }^{\mathrm{b}}$ Assistant Professor - Department of Civil Engineering, Babol University of technology, Babol, Iran.

${ }^{c}$ Associate Professor - Department of Civil Engineering, Babol University of technology, Babol, Iran.

d PhD Student - Department of Civil Engineering, Babol University of technology, Babol, Iran.

Received 22 Sep 2012

In revised form 25 Mar 2013

*Author email: tavakoli@nit.ac.ir 


\section{INTRODUCTION}

Thin-walled structures represent complicated dynamic behavior, and their seismic assessment is a challenging problem in earthquake engineering. These complications are magnified in case of steel tanks where the fluid-structure interaction issues involve. ASSTs are an example which have been constructed over centuries, and are extensively used to store a variety of liquids, e.g. water for drinking and firefighting purposes, petroleum, chemicals, and liquefied natural gas. Nowadays ASSTs have become a major topic in seismic engineering world. Analytical studies were first accomplished by Jacobsen and Housner (late 1940s to early 1960s). Some equations considering effective hydrodynamic mass and mass moment of the contents of cylindrical tanks subjected to horizontal translation were developed by Jacobsen, 1949. Housner, 1963 devised a simplified method for estimating liquid response in rigid seismically-excited rectangular and cylindrical tanks. Edwards, 1969 was the first researcher to consider tank's flexibility in establishing hydrodynamic forces on ground-supported cylindrical tanks subjected to horizontal earthquake ground motions, and to employ the finite element technique to dynamic analysis of liquid storage tanks. Many investigations (Shaban and Nash, 1975; Kana and Dodge, 1975; Haroun, 1980; Attari and Rofooei, 2008; Kalani sarokolayi and Navayineya, 2008; Moslemi, Kianoush and Pogorzelski, 2011) have been conducted for analyzing water storage tanks under translational components of the ground motion. Actually earthquakes movements cause translational components generated during a seismic event are always being accompanied by rotational components due to traveling wave effects. The engineering significance of rotational components of strong seismic motion at the ground surface was noted during the late 60s and early 70s of the last century (e.g., Newmark and Hall, 1969; Newmark and Rosenblueth, 1971). Tombstones and stone lanterns are reported to be rotated during large earthquakes (e.g., Yamaguchi and Odaka, 1974). The importance of torsional components in seismic analysis and design of structures are highlighted in several studies (Bielak 1978, Abdel Gaffar and Rubin 1984, Ghafory-Ashtiany and Singh 1986, Gupta and Trifunac 1989, Goel and Chopra 1994, Takeo 1998, Shakib and Tohidi 2002, Ghayamghamian et al, 2009; Falamarz-Sheikhabadi and GhaforyAshtiany 2012, Kalani sarokolayi et al 2012).

In conventional earthquake engineering, ASSTs are designed to resist only against simplified representation of the ground motion of strong earthquakes in terms of its three translational components, which could only be measured directly. However, the motion of a point can be completely characterized by its six components: three translations and three rotations. Precedent studies on the seismic behavior of well-designed structures being exposed to strong ground motions have distinguished that earthquake damages or even collapse of structures cannot be ascribed to the translational components only. Detailed analysis of structural damage during numbers of earthquakes, e. g. Mexico, 1985, Loma Prieta, 1989, Killari, 1993 and Bhuj, 2001 has indicated that the damage is often due to the additional stresses caused by the torsional response. During the San Fernando earthquake of 1971, the torsional response of tall buildings in Los Angeles was attributed to torsional excitation (Trifunac, 2006). In the research conducted by Avad and Humar, 1984, it is revealed that even the symmetric structures can be expected to undergo substantial torsional excitation during an earthquake.

Latin American Journal of Solids and Structures 10(2013) $1155-1176$ 
A simple relationship between the torsional and translational components of a motion, which was based on the assumption of a constant wave velocity of propagation, seems to be initially established by Newmark, 1969. More rational methods have been developed by Trifunac, 1982, Lee and Trifunac $(1985,1987)$, and Castellani and Boffi $(1986,1989)$, where not only the requirement of a constant plane wave velocity of propagation was overlooked but dispersion of the waves and their transient arrival times in an elastic half-space were considered. In fact, the frequencies of the impinging harmonics of the ground motion essentially influence on the angle of incidence. A comprehensive method should be applied for calculating rotational components from the corresponding translational components, in which dependence of the angle of incidence plus the velocity of propagation of the wave on the frequency of the harmonics constituting the ground motion at a specific site is definitely considered. Using an improved approach proposed by Li et al, 2004, the rotational components of a seismic ground motion can be obtained; in this method, the effect of relative contributions of $P, S V$, and $S H$ waves are included for determining time histories of rotational components.

The frequency of the wave motion and the angle of incidence are two substantial factors which define the value of the wave's velocity. Generally, it can be properly assumed that in a specific seismic wave on the site not far from the earthquake source the content of $S$ wave is primary concern rather than neglecting the content of $P$ wave (Li et al, 2004). In this paper, both $S V$ and $S H$ waves were considered to obtain three rotational components of earthquake which were resulted by three translational components; in subsequence, an improvement in the approach proposed by Li et al, 2004 based on $S V$ and $S H$ wave incidence was proposed. The constitutive model of steel material is also an important issue to be regarded for linear dynamic analysis of structures such as aboveground steel tanks subjected to the six components of earthquake. The fluid-structure interaction should also be considered in dynamic analysis of fluid container structures. Owing to its simplicity, the Lagrangian approach has been employed by several researchers (Hamdi, 1978; Khalvati and Wilson, 1983; Ahmadi and Navayineya, 1995; Kalani Sarokolayi and Navayineya, 2008; Akkose, Adanur, Alemdar and Dumanoglu, 2008). In this research, simple and accurate LagrangianLagrangian equation was employed for considering fluid-structure interaction in finite element mesh of fluid and structure domains. Availability of only three translational components of accelerogram and a rigid foundation for structure was assumed. As a result of the latter assumption, the soilstructure interaction was neglected. It was assumed that the water medium was homogenous, inviscid, and irrotational, while the material of the structure is isotropic and homogenous. In analyses, small displacements and material linearity are assumed. Nevertheless, the water behavior was considered linear, and cavitation effect in fluid domain was overlooked (El-Aidi and Hall, 1989). The theory of three-dimensional isotropic elastic propagation of the wave in the soil was also considered.

\section{CHARACTERISTICS OF ROTATIONAL COMPONENTS}

\subsection{Rotational components due to body waves}

Seismic ground motions are direct result of plane harmonic waves arriving at the site close to the earthquake source. It is assumed that direction of propagation of the waves lies in the vertical $(x$, $z$ ) plane. As the wave passes, it induces particle displacement in the perpendicular and parallel 
planes to the direction of propagation. The particle displacements in the plane which are perpendicular to the direction of propagation are decomposed into in-plane and out-of-plane components due to $S V$ and $S H$ waves, respectively. The parameters, $A_{S}$ and $A_{0}$ depict amplitudes of in-plane and out-of-plane components, respectively. Incidence and reflection of the body waves will originate three rotational components of the ground motion at the free surface: $\varphi_{g z}, \varphi_{g x}, \varphi_{g y}$. The component $\varphi_{g z}$, referred to as torsional component, is related to rotation about $z$ axis; and the components $\varphi_{g x}$ and, $\varphi_{g y}$ referred to as the rocking components, are related to rotation about $x$ axis and $y$ axis, respectively.

\subsubsection{Incidence SV waves}

The coordinate system $(x, z)$ and the incident and reflected rays associated with plane $S V$ wave, reflecting off the free boundary of the elastic homogeneous and isotropic half space $(Z \leq 0)$ are shown in Figure (1-a). Alongside preserving generality, it is assumed here that the incident and reflected rays are in the plane of $Y=0$. Amplitude of particle motion, $u$ and $w$, along with the ray direction are presented by $A_{S}, A_{S S}$ and $A_{S P}$. It is assumed that the ray direction demonstrated positive displacement amplitudes. $A_{S}, A_{S S}$, and $A_{S P}$ corresponded to incident $S V$ wave, reflected $S V$ wave, and reflected $P$ wave, respectively. Considering this kind of excitation and coordination, the only definable non-zero components of motion located at $Y=0$ planes are:

(a)

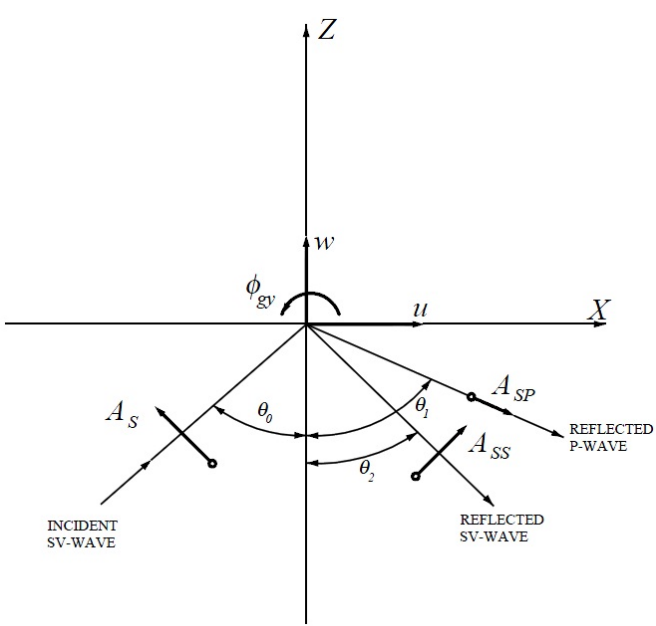

(b)

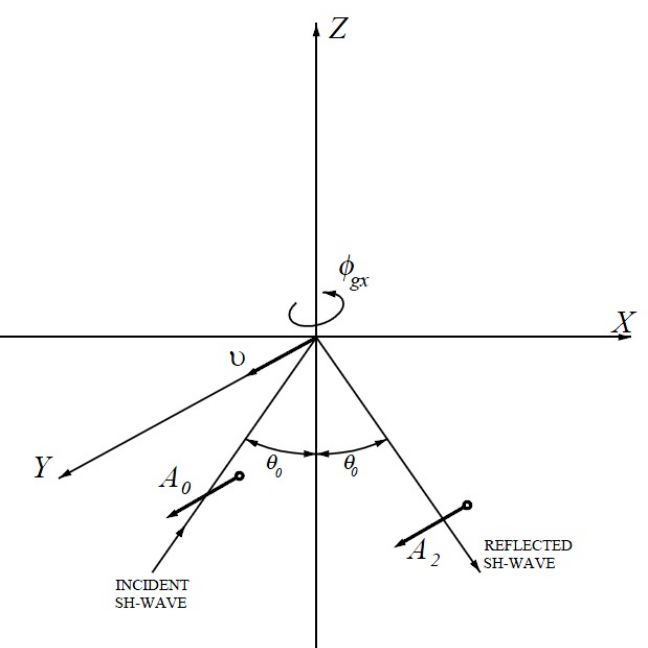

Figure 1 Propagation of (a) incident SV wave, (b) incident $S H$ wave.

The particles of displacement $u, w$ in the $x, z$ directions, respectively, are given by:

$$
\begin{aligned}
& u=\frac{\partial \phi_{S P}}{\partial x}+\frac{\partial\left(\psi_{S V}+\psi_{S S}\right)}{\partial z} \\
& w=\frac{\partial \phi_{S P}}{\partial z}-\frac{\partial\left(\psi_{S V}+\psi_{S S}\right)}{\partial x}
\end{aligned}
$$


The relation between the rotational and translational motions in a point base on the classical elasticity theory can be expressed by:

$$
\varphi_{g y}=\frac{1}{2}\left(\frac{\partial w}{\partial x}-\frac{\partial u}{\partial z}\right)
$$

In the above equations for frequency of harmonic waves, i. e. $\omega$, the potential functions are:

$$
\begin{aligned}
& \psi_{S V}=A_{S} \exp i \omega\left(\frac{\sin \theta_{0}}{\beta} x-\frac{\cos \theta_{0}}{\beta} z-t\right) \\
& \phi_{S P}=A_{S P} \exp i \omega\left(\frac{\sin \theta_{1}}{\alpha} x+\frac{\cos \theta_{1}}{\alpha} z-t\right) \\
& \psi_{S S}=A_{S S} \exp i \omega\left(\frac{\sin \theta_{0}}{\beta} x+\frac{\cos \theta_{0}}{\beta} z-t\right)
\end{aligned}
$$

Where $\alpha$ and $\beta$ are the propagation velocities of $P$ and $S$ waves, respectively. They can be expressed as follows (Datta, 2010):

$$
\begin{gathered}
\alpha=\left[\frac{E}{\rho} \frac{1-v}{(1+v)(1-2 v)}\right]^{\frac{1}{2}} \\
\beta=\left[\frac{G}{\rho}\right]^{\frac{1}{2}}=\left[\frac{E}{\rho} \frac{1}{(1+v) 2}\right]^{\frac{1}{2}}
\end{gathered}
$$

In which $E, G, \varrho$ and $\nu$ are the Young's modulus, the shear modulus, the mass density, and the Poisson ratio of the soil mass, respectively. The value of coefficients, $\alpha$ and $\beta$, depends on the soil properties; at the surface of the earth, their values varies in the range of 5 to $7 \mathrm{~km} . \mathrm{s}^{-1}$ and 3 to $4 \mathrm{~km} . \mathrm{s}^{-1}$, respectively (Datta, 2010). According to Figure 1, the angle of incidence, $\theta_{0}$, and the angle of reflection of $S V$ waves, $\theta_{2}$, are equal. The angle of reflected $P$ wave is denoted as $\theta_{1}$. By imposing the free shear stress condition at the ground surface:

$$
\left.\tau_{x z}\right|_{z=0}=\left[\frac{\partial w}{\partial x}+\frac{\partial u}{\partial z}\right]_{z=0}=0
$$

The rocking component can be obtained from Eq. (1) to Eq. (9) as: 


$$
\begin{aligned}
& \varphi_{g y}=\frac{\partial w}{\partial x}=\frac{\partial^{2} \phi_{S P}}{\partial z \partial x}-\frac{\partial^{2}\left(\psi_{S V}+\psi_{S S}\right)}{\partial^{2} x} \\
& =i \omega \frac{\cos \theta_{1}}{\alpha} i \omega \frac{\sin \theta_{1}}{\alpha} \phi_{S P}-\left[\left(i \omega \frac{\sin \theta_{0}}{\beta}\right) \psi_{S V}\right. \\
& \left.+\left(i \omega \frac{\sin \theta_{0}}{\beta}\right)^{2} \psi_{S S}\right]
\end{aligned}
$$

According to the Snell's law, $\left(\sin \theta_{0}\right) / \beta=\left(\sin \theta_{1}\right) / \alpha$, Eq. (11) can be obtained:

$$
\phi_{g y}=\frac{i \omega}{C_{x}} w=\left(1 e^{\frac{\pi}{2} i}\right)\left(\frac{\omega}{C_{x}}\right)\left(R_{w} \cdot e^{i \theta_{w}}\right)=\left(\frac{\omega}{C_{x}} R_{w}\right)\left(e^{\left(\frac{\pi}{2}+\theta_{w}\right) i}\right)
$$

In which $C_{x}=\beta / \sin \theta_{0}, R_{w}$ and $\theta_{w}$ are translational component and its phase.

These equations can also be applied for the other rocking component, $\varphi_{g x}$.

\subsubsection{Incidence $\mathrm{SH}$ waves}

According to Figure (1-b), there is no mode conversion in the case of incident $S H$ wave; hence, there is only one reflected $S H$ wave with $\theta_{2}=\theta_{0}$ and $A_{2}=A_{0}$.

The potential functions of incident and reflected waves are:

$$
\begin{aligned}
& V_{S H}=A_{0} \exp i \omega\left(\frac{\sin \theta_{0}}{\beta} x-\frac{\cos \theta_{0}}{\beta} z-t\right) \\
& V_{S H^{\prime}}=A_{1} \exp i \omega\left(\frac{\sin \theta_{0}}{\beta} x+\frac{\cos \theta_{0}}{\beta} z-t\right)
\end{aligned}
$$

Displacement field $v$, which is caused by the incident and reflected waves in $y$ direction is:

$$
v=2 V_{S H}=2 A_{0} \exp i \omega\left(\frac{\sin \theta_{0}}{\beta} x-t\right)
$$

Since $u$ does not depend on the out-of-plane coordinate, the consideration of Eq. (11) to Eq. (14) leads to the torsional component, $\varphi_{g z}$ :

$$
\begin{aligned}
& \varphi_{g z}=\frac{1}{2}\left(\frac{-\partial u}{\partial y}+\frac{\partial v}{\partial x}\right)=\left.\frac{1}{2} \frac{\partial v}{\partial x}\right|_{Z=0}=\frac{\partial V_{S H}}{\partial x} \Rightarrow \varphi_{g z}=i \omega \frac{\sin \theta_{0}}{\beta} \frac{v}{2}=\frac{i \omega}{2 C_{x}} v \Rightarrow \\
& \Rightarrow \varphi_{g z}=\left(1 e^{\frac{\pi}{2} i}\right)\left(\frac{\omega}{2 C_{x}}\right)\left(R_{v} \cdot e^{i \theta_{v}}\right)=\left(\frac{\omega}{2 C_{x}} R_{v}\right)\left(e^{\left(\frac{\pi}{2}+\theta_{v}\right) i}\right)
\end{aligned}
$$


In which $C_{x}=\beta / \sin \theta_{0}, R_{v}$ and $\theta_{v}$ are translational component and its phase. It is assumed that the translational components $\mathrm{u}, \mathrm{v}$ and $\mathrm{w}$ of the ground motion at the free surface are available through measurements. Eq. (11) and (15) could be used to define the rocking and torsional components of ground motion, respectively. These equations show that the amplitude of rotational components are related to translational components amplitude, $\left(\frac{\omega}{C_{x}} R_{w}\right)$ or $\left(\frac{\omega}{2 C_{x}} R_{v}\right)$, and their phase difference is $\frac{\pi}{2}$. However, this is not feasible with the state-of-the-art seismology yet. Therefore, in order to apply these equations to define $\varphi_{g y}, \varphi_{g z}$, the value of incident angle $\theta_{0}$ should be identified. How to determine unknown parameters is the subject of the following development.

\subsection{Incidence angle of $\mathrm{SV}$ and $\mathrm{SH}$ waves}

A modification of a developed approach by Hong-Nan Li and et al (2004) was used to calculate the angle of incident waves. Using this approach while introducing $\left(x=\sin \theta_{0}\right)$ as well as considering Snell's law, Eq. (14) and (15) were employed to obtain the angle of incident $S V$ and $S H$ waves.

$$
\begin{gathered}
G=\frac{2 x \sqrt{1-K^{2} x^{2}}}{K\left(1-2 x^{2}\right)}, \theta_{0}<\theta_{C} \\
G=-\frac{2 x \sqrt{1-K^{2} x^{2}}}{i K\left(1-2 x^{2}\right)}, \theta_{0}>\theta_{C}
\end{gathered}
$$

where $G=\operatorname{tg} \bar{e}=w / u$ and $G=\operatorname{tg} \bar{e}=w / v$ are related to rocking component in $x-z$ and $y$ - $z$ plane due to $S V$ waves, respectively; $G=\operatorname{tg} \bar{e}=v / u$ is related to torsional component in $x-y$ plane due to $S H$ waves; $K=\alpha / \beta$, and $\theta_{C}=\arcsin (\beta / \alpha)$ is the incident critical angle.

\section{FINITE ELEMENT MODEL}

In the finite element method based on displacement (Lagrangian-Lagrangian method), the particle displacement is regarded as the key variable for solid and fluid domains. Applying LagrangianLagrangian method for coupled fluid-structure systems, the following principal dynamic equation can be achieved (El-Aidi and Hall, 1989):

$$
M \ddot{u}+C \dot{u}+K u=F(t)
$$

where $M, C$ and $K$, indicate mass matrix, damping matrix and stiffness matrix for the coupled system, respectively. In this coupled system, the parameters $\ddot{u}, \dot{u}, u$, and $F(t)$ denote vectors of accelerations, velocities, displacements and external loads, respectively. The six earthquake com- 
ponents must be involved for defining the force vector of $F(t)$ (Chopra, 2008). For establishing Lagrangian fluid elements, the shear modulus was set to zero, and the fluid bulk modulus, $\mathrm{K}_{\mathrm{B}}$, was used to obtain the elastic stress-strain relations using the stiffness matrix as follows:

$$
\left\{\begin{array}{c}
\varepsilon_{b u l k} \\
\gamma_{x y} \\
\gamma_{y z} \\
\gamma_{x z} \\
R_{x} \\
R_{y} \\
R_{z}
\end{array}\right\}=\left[\begin{array}{ccccccc}
1 / K_{B} & 0 & 0 & 0 & 0 & 0 & 0 \\
0 & 1 / S & 0 & 0 & 0 & 0 & 0 \\
0 & 0 & 1 / S & 0 & 0 & 0 & 0 \\
0 & 0 & 0 & 1 / S & 0 & 0 & 0 \\
0 & 0 & 0 & 0 & 1 / B & 0 & 0 \\
0 & 0 & 0 & 0 & 0 & 1 / B & 0 \\
0 & 0 & 0 & 0 & 0 & 0 & 1 / B
\end{array}\right] \times\left\{\begin{array}{c}
P \\
\tau_{x y} \\
\tau_{y z} \\
\tau_{x z} \\
M_{x} \\
M_{y} \\
M_{z}
\end{array}\right\}
$$

where $\varepsilon_{b u l k}=\frac{\partial u}{\partial x}+\frac{\partial v}{\partial y}+\frac{\partial w}{\partial z}$ is bulk strain, $P$ is pressure, $\gamma$ is the shear strain, $S=B=K_{B} \times 10^{-9}$ (arbitrarily small number to set some small shear and rotational stability), $\tau$ is shear stress, $R_{i}$ and $M_{i}$ are rotation and twisting force about axis $i$ respectively. The damping matrix of the fluid element which relates the strain rates (strain differentiation with respect to time) to the stresses can be defined as follows:

$$
\left\{\begin{array}{c}
\dot{\varepsilon}_{b u l k} \\
\dot{\gamma}_{x y} \\
\dot{\gamma}_{y z} \\
\dot{\gamma}_{x z} \\
\dot{R}_{x} \\
\dot{R}_{y} \\
\dot{R}_{z}
\end{array}\right\}=\left[\begin{array}{ccccccc}
0 & 0 & 0 & 0 & 0 & 0 & 0 \\
0 & 1 / \eta & 0 & 0 & 0 & 0 & 0 \\
0 & 0 & 1 / \eta & 0 & 0 & 0 & 0 \\
0 & 0 & 0 & 1 / \eta & 0 & 0 & 0 \\
0 & 0 & 0 & 0 & 1 / C & 0 & 0 \\
0 & 0 & 0 & 0 & 0 & 1 / C & 0 \\
0 & 0 & 0 & 0 & 0 & 0 & 1 / C
\end{array}\right] \times\left\{\begin{array}{c}
P \\
\tau_{x y} \\
\tau_{y z} \\
\tau_{x z} \\
M_{x} \\
M_{y} \\
M_{z}
\end{array}\right\}
$$

where $\eta$ is viscosity and $C=0.00001 \times \eta$. The mass matrix of the fluid element can be also obtained as lumped mass matrix (Moslemi, Kianoush and Pogorzelski, 2011). For Lagrangian solid elements, the structural damping, $C_{S}$ is defined by following equation which is known as Rayleigh expression:

$$
\left[C_{S}\right]=\alpha_{1}\left[M_{S}\right]+\beta_{1}\left[K_{S}\right]
$$

where the proportionality constants, $\alpha_{1}$ and $\beta_{1}$ may be determined by specifying the two damping ratios of the tank, corresponding to two different frequencies (El-Aidi and Hall, 1989): 


$$
\begin{aligned}
& \alpha_{1}=2 \omega_{1} \xi_{1}-\left(\omega_{1}^{2} \beta_{1}\right) \\
& \beta_{1}=2 \frac{\left(\xi_{1} \omega_{1}-\xi_{2} \omega_{2}\right)}{\left(\omega_{1}^{2}-\omega_{2}^{2}\right)}
\end{aligned}
$$

$K_{s}$ and $M_{s}$ are also the stiffness and lumped mass matrices, respectively. To solve Eq. (18), Newmark method (Chopra, 2008) is applied in the finite element formulation for dynamic analysis.

\section{NUMERICAL RESULTS}

Geometrical characteristics and finite element model of considered structures are represented in Figure 2.

(a)

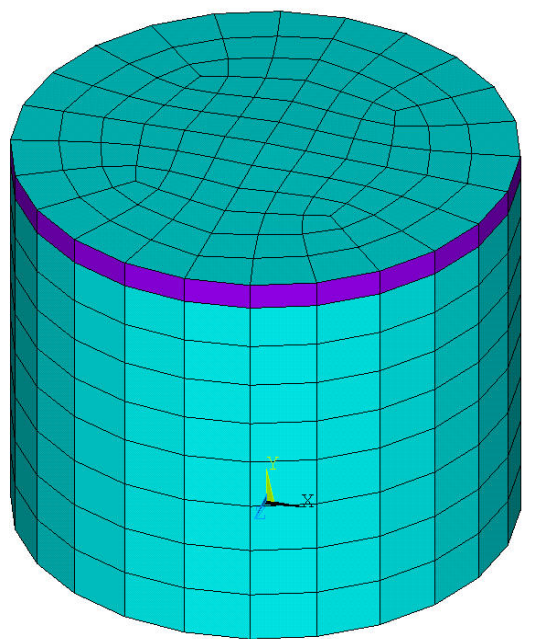

(b)

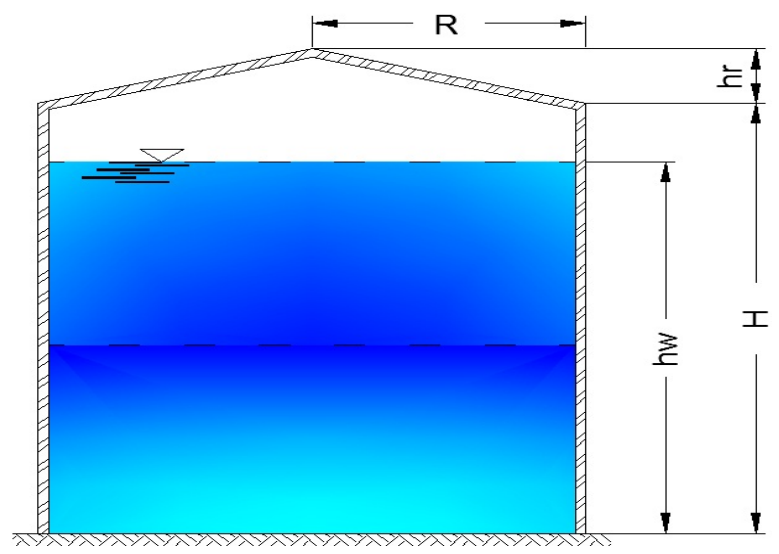

Figure 2 (a) Finite element model of ASSTs, (b) Geometrical characteristics

Table 2 presents geometrical characteristics $\left(R, H, h_{r}, h_{w}\right)$ of the structures shown in Figure (2-b) which are related to one finite element model of ASSTs:

Table 1 Geometrical characteristics of ASSTs

\begin{tabular}{lllll|}
\hline FEM & $\mathrm{R}(\mathrm{m})$ & $\mathrm{H}(\mathrm{m})$ & $\mathrm{h}_{\mathrm{w}}(\mathrm{m})$ & $\mathrm{h}_{\mathrm{r}}(\mathrm{m})$ \\
\hline Empty & 4.85 & 7.9 & 0 & 0.123 \\
Half & 4.85 & 7.9 & 3.95 & 0.123 \\
Full & 4.85 & 7.9 & 7.392 & 0.123
\end{tabular}

Linear constitutive properties of material of the tank at ambient temperature were assumed to be as follows: Young modulus of steel, $E_{S}=200 \mathrm{GPa}$, Poison's ratio of steel is 0.27 and the mass density of steel and water were $2400 \mathrm{~kg} / \mathrm{m}^{3}$ and $1000 \mathrm{~kg} / \mathrm{m}^{3}$, respectively. Bulk modulus of elasticity is 2.2GPa. A finite element analysis was accomplished to determine the dynamic response of 
the ASSTs during earthquake. Using shell elements with four nodes and solid elements with eight nodes, the tank and the contained fluid were meshed; each node had three degrees of freedom. The damping coefficient in the structure domain was maintained at $5 \%$ and the viscosity of fluid was considered 1\% (El-Aidi and Hall, 1989). Full transient analysis was performed to determine the dynamic responses of ASSTs subjected to three and six components of earthquake. For this purpose, three translational components of six earthquakes have been used to derive the time histories of the corresponding rotational components. Characteristics of these earthquakes are summarized in Table 2. These earthquakes are selected such a way that they have been different PGA, shear wave velocities and epicentral distances. Fast Fourier transform was applied to time histories of translational motions with different discrete frequencies for these earthquakes; in this case, related rotational components could be obtained. It was assumed that the recorded motions were primarily generated by shear waves (Hong-Nan Li and et al, 2004). Therefore, Eq. (16) and (17) were used to calculate the angles of incidence for each harmonic component, which were depended on frequency. Knowing the angle of incidence, the rotational components at each discrete frequency could be obtained from Eq. (11) and (15) that they are related to the rocking and torsional components, respectively. This process was followed for calculating the Fourier spectra of the rotational components at all discrete frequencies. In subsequence, the rotational time histories were achieved from inverse Fourier transform of these spectra. The time history of rocking and torsional components for earthquakes of Table 2 are obtained using improved approach and mentioned comments in MATLAB software.

Table 2 Earthquake characteristics

\begin{tabular}{|c|c|c|c|c|c|c|}
\hline Number & Earthquake & Station & $\begin{array}{c}\text { Record } \\
\text { Component }\end{array}$ & $\begin{array}{l}\text { PGA } \\
(\mathrm{g})\end{array}$ & $\begin{array}{l}\text { Epicentral dis- } \\
\text { tance }(\mathrm{km})\end{array}$ & $\begin{array}{c}\text { Shear Wave Ve- } \\
\text { locity }(\mathrm{m} / \mathrm{s})\end{array}$ \\
\hline 1 & $\begin{array}{c}\text { Chi-Chi Taiwan } \\
1999 / 09 / 20\end{array}$ & ALS & $\begin{array}{l}\text { ALS-V } \\
\text { ALS-E } \\
\text { ALS-N }\end{array}$ & $\begin{array}{l}0.073 \\
0.183 \\
0.163\end{array}$ & 37.83 & 553.40 \\
\hline 2 & $\begin{array}{c}\text { Imperial Valley } \\
1979 / 10 / 15\end{array}$ & $\begin{array}{c}958 \\
\text { El Centro Array } \\
\# 8\end{array}$ & $\begin{array}{l}\text { H-E08-UP } \\
\text { H-E08140 } \\
\text { H-E08230 }\end{array}$ & $\begin{array}{l}0.439 \\
0.602 \\
0.454 \\
\end{array}$ & 28.09 & 206.10 \\
\hline 3 & $\begin{array}{c}\text { Kern County } \\
1952 / 07 / 21\end{array}$ & $\begin{array}{c}1095 \\
\text { Taft Lincoln } \\
\text { School }\end{array}$ & $\begin{array}{l}\text { TAF-UP } \\
\text { TAF021 } \\
\text { TAF111 }\end{array}$ & $\begin{array}{l}0.109 \\
0.156 \\
0.178\end{array}$ & 43.49 & 385.40 \\
\hline 4 & $\begin{array}{l}\text { Northridge } \\
1994 / 01 / 17\end{array}$ & $\begin{array}{c}00000 \\
\text { LA Dam }\end{array}$ & $\begin{array}{l}\text { LDM-UP } \\
\text { LDM064 } \\
\text { LDM334 }\end{array}$ & $\begin{array}{l}0.424 \\
0.511 \\
0.349\end{array}$ & 11.79 & 629.00 \\
\hline 5 & $\begin{array}{c}\text { San Fernando } \\
1971 / 02 / 09\end{array}$ & $\begin{array}{c}279 \\
\text { Pacoima Dam }\end{array}$ & $\begin{array}{c}\text { PCDDWN } \\
\text { PCD164 } \\
\text { PCD254 } \\
\end{array}$ & $\begin{array}{c}0.699 \\
1.226 \\
1.16 \\
\end{array}$ & 11.86 & 2016.10 \\
\hline 6 & $\begin{array}{l}\text { Tabas, Iran } \\
1978 / 09 / 16\end{array}$ & 70 Boshrooyeh & $\begin{array}{l}\text { BOS-V1 } \\
\text { BOS-L1 } \\
\text { BOS-T1 }\end{array}$ & $\begin{array}{l}0.085 \\
0.107 \\
0.089\end{array}$ & 74.66 & 338.60 \\
\hline
\end{tabular}

Latin American Journal of Solids and Structures 10(2013) $1155-1176$ 
According to the Table 2, in this paper the soil type under the tanks and its effect on the response of ASSTs was investigated with considering the types of the shear waves' velocity. In the other words, the effect of soil type were considered in producing rocking and torsional acceleration components of earthquakes on the basis of transitional components using the equations (11) and (15); it was feasible by studying a wide range of average shear wave velocities from about 200 $\mathrm{m} / \mathrm{s}$ to $2000 \mathrm{~m} / \mathrm{s}$ in top 30 meters of soil layers in three soil types of A, C, and D (mostly close to E). As shown in Table 3, specifications of these soil types were determined in accordance with NEHRP Site Classification:

Table 3 NEHRP Site Classification, FEMA 450-1 / 2003 Edition

\begin{tabular}{ccc|}
\hline Site Class & Description & $\bar{v}_{s}$ \\
\hline A & Hard rock & $\geq 5000 \mathrm{ft} / \mathrm{sec}(\geq 1500 \mathrm{~m} / \mathrm{s})$ \\
B & Rock & 2500 to $5000 \mathrm{ft} / \mathrm{sec}(760$ to $1500 \mathrm{~m} / \mathrm{s})$ \\
C & Very dense soil and soft rock & 1200 to $2500 \mathrm{ft} / \mathrm{sec}(360$ to $760 \mathrm{~m} / \mathrm{s})$ \\
D & Stiff soil & 600 to $1200 \mathrm{ft} / \mathrm{sec}(180$ to $360 \mathrm{~m} / \mathrm{s})$ \\
E & Soft clay soil & $\leq 600 \mathrm{ft} / \mathrm{sec}(\leq 180 \mathrm{~m} / \mathrm{s})$ \\
\hline
\end{tabular}

For SI: $1 \mathrm{ft}=0.3048$ meter

The peak rotation rate of these earthquakes, their predominant frequencies and Fourier power spectrum are listed in Table 4 and their rotational time histories are shown in Figure (3).

Table 4 rotational characteristics of earthquakes

\begin{tabular}{|c|c|c|c|c|c|c|}
\hline \multirow[b]{2}{*}{ Earthquake } & \multicolumn{2}{|c|}{$\begin{array}{c}\text { peak rotation rate } \\
\left(\mathrm{mrad} / \mathrm{s}^{2}\right)\end{array}$} & \multicolumn{2}{|c|}{$\begin{array}{l}\text { Predominant Frequency } \\
\qquad(\mathrm{Hz})\end{array}$} & \multicolumn{2}{|c|}{$\begin{array}{c}\text { Power Amplitude } \\
(1 / \mathrm{s})\end{array}$} \\
\hline & $\begin{array}{c}\text { Rocking } \\
\text { Compo- } \\
\text { nent }\end{array}$ & $\begin{array}{c}\text { Torsional } \\
\text { Compo- } \\
\text { nent }\end{array}$ & $\begin{array}{c}\text { Rocking } \\
\text { Compo- } \\
\text { nent }\end{array}$ & $\begin{array}{c}\text { Torsional } \\
\text { Compo- } \\
\text { nent }\end{array}$ & $\begin{array}{c}\text { Rocking } \\
\text { Compo- } \\
\text { nent }\end{array}$ & $\begin{array}{c}\text { Torsional } \\
\text { Compo- } \\
\text { nent }\end{array}$ \\
\hline $\begin{array}{l}\text { Chi-Chi } \\
\text { Taiwan }\end{array}$ & -11.61 & 9.43 & 0.769 & 4.077 & 0.098 & 0.111 \\
\hline $\begin{array}{c}\text { Imperial } \\
\text { Valley }\end{array}$ & 273.44 & 153.91 & 0.61 & 0.244 & 0.12 & 0.1334 \\
\hline $\begin{array}{c}\text { Kern Coun- } \\
\text { ty } \\
\end{array}$ & -12.88 & -10.56 & 0.68 & 0.6836 & 0.3327 & 0.3497 \\
\hline Northridge & -447.62 & -68.58 & 1.1 & 95.04 & 0.0437 & 0.039 \\
\hline $\begin{array}{c}\text { San Fernan- } \\
\text { do } \\
\end{array}$ & -51.39 & -32.52 & 11.23 & 13 & 0.0435 & 0.036 \\
\hline Tabas & 27.49 & 14.52 & 0.24 & 0.59 & 0.1085 & 0.156 \\
\hline
\end{tabular}

$1 \mathrm{mrad}=0.001 \mathrm{rad}$ 
As shown in Table 4, the Imperial Valley earthquake has a high rotation rate and Power Amplitude of rocking and torsional components. The Northridge earthquake has also a high rotation rate and the Tabas earthquake has also a high Power Amplitude but other earthquakes have a lower amount of these parameters. These two parameters can be affected on the response of structure subjected to rotational components of earthquake and related to natural frequency of structure; the resonance phenomena can be occurred.

(a)

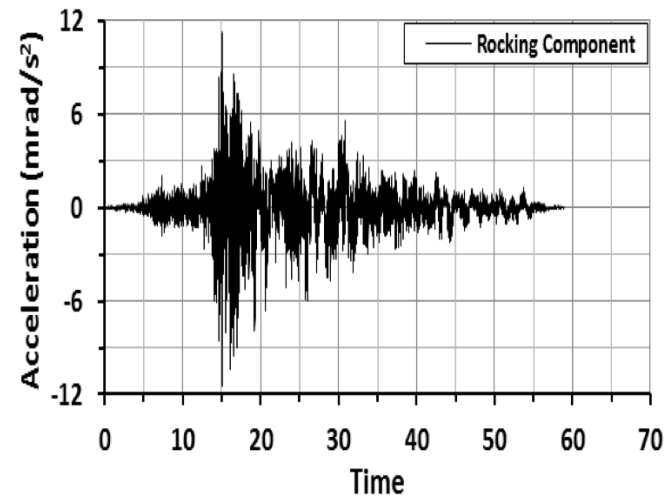

(b)

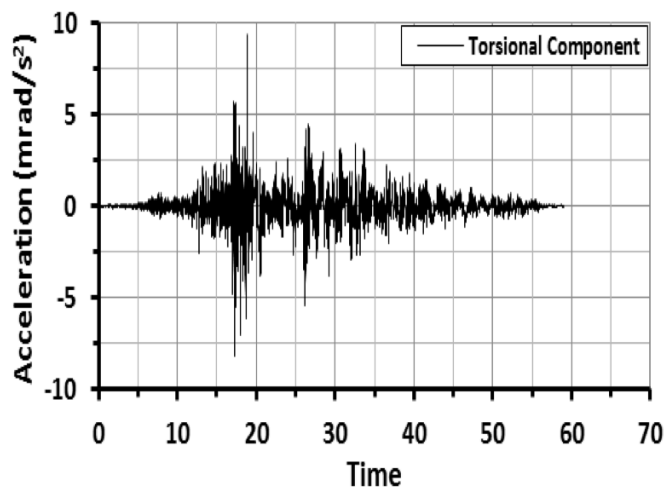

Chi-Chi Taiwan, 1999/09/20

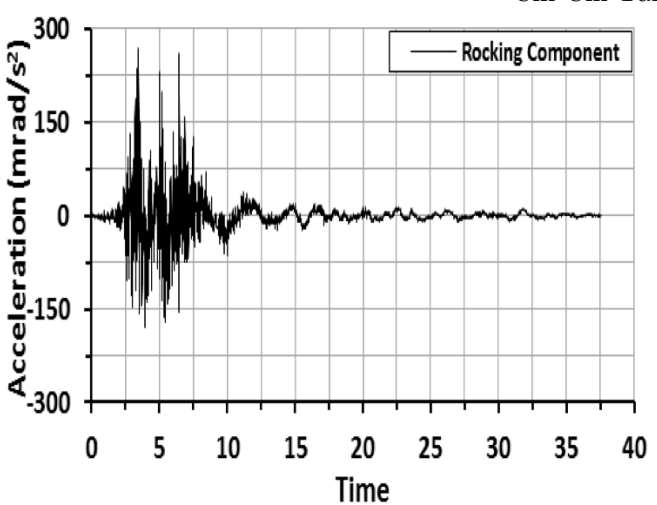

(b)

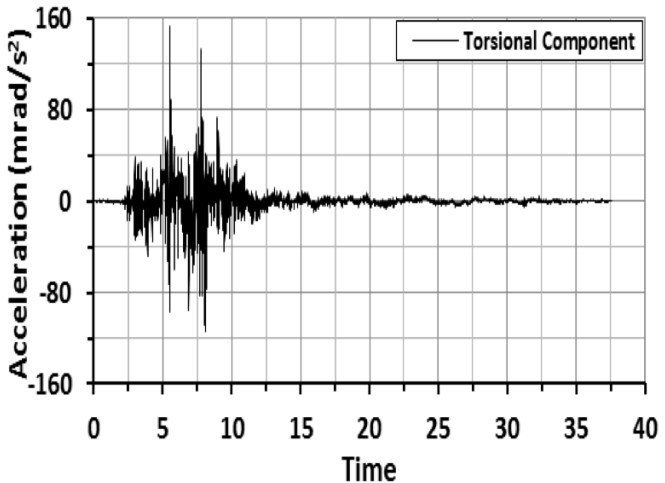

Imperial Valley, 1979/10/15

(a)

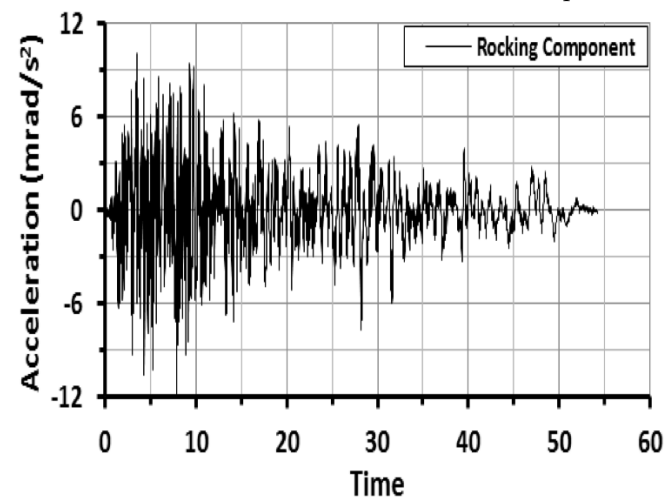

(b)

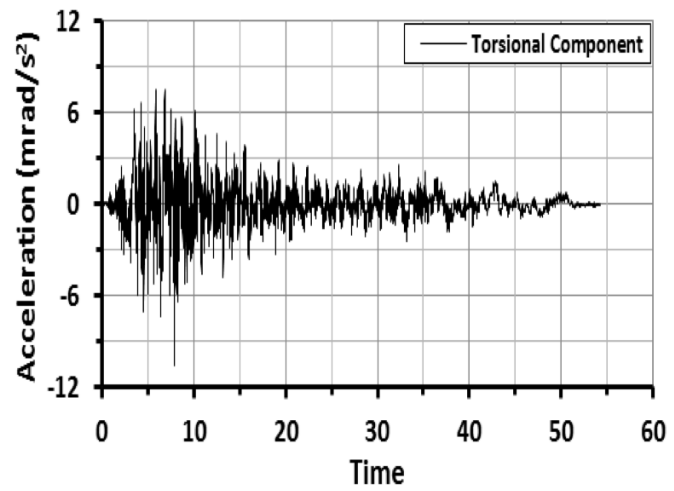

Kern County, 1952/07/21

Figure 3 (a) time history of rocking components, (b) time history of torsional components 
(a)

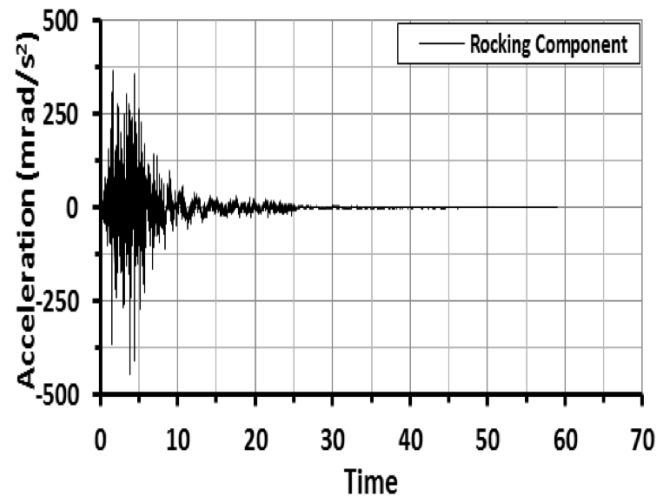

(b)

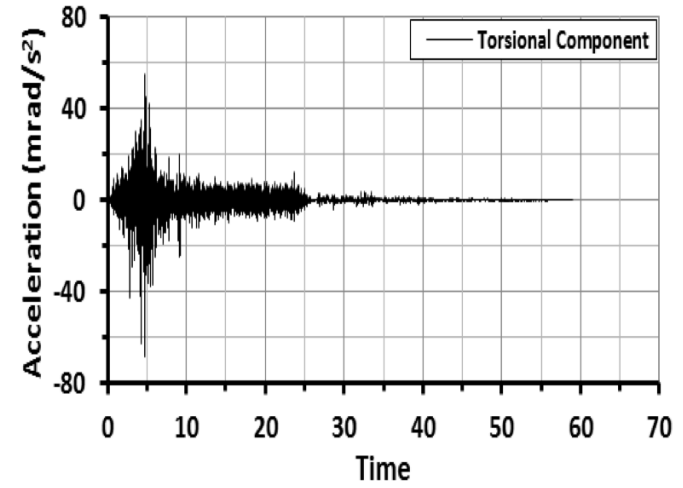

Northridge, 1994/01/17

(a)

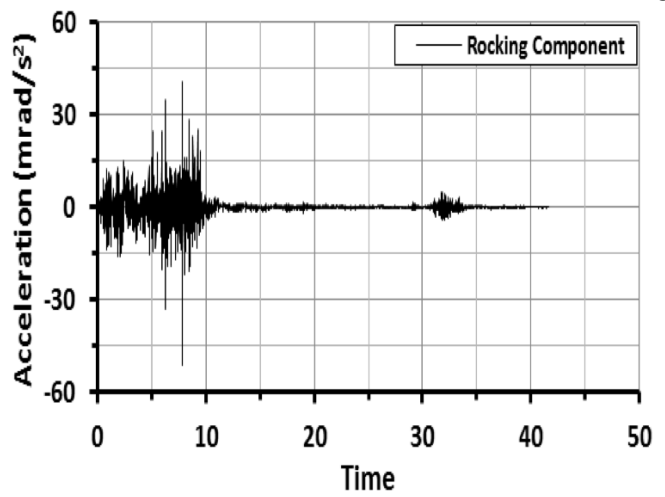

(b)

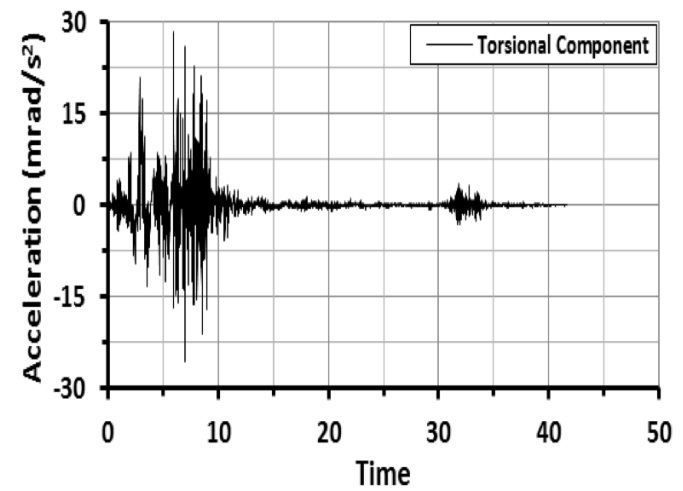

San Fernando, 1971/02/09

(a)

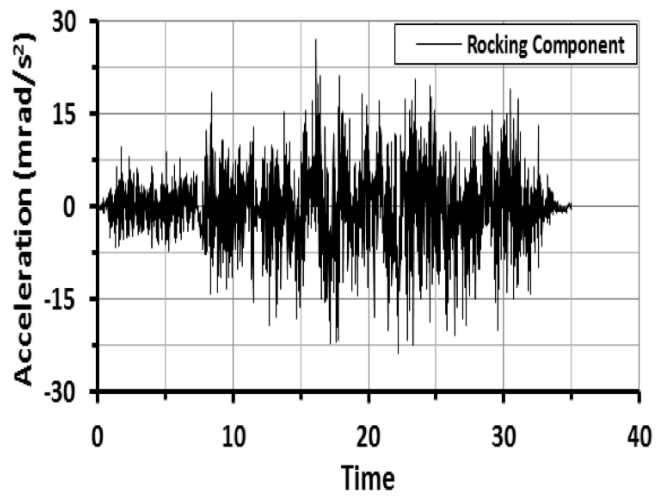

(b)

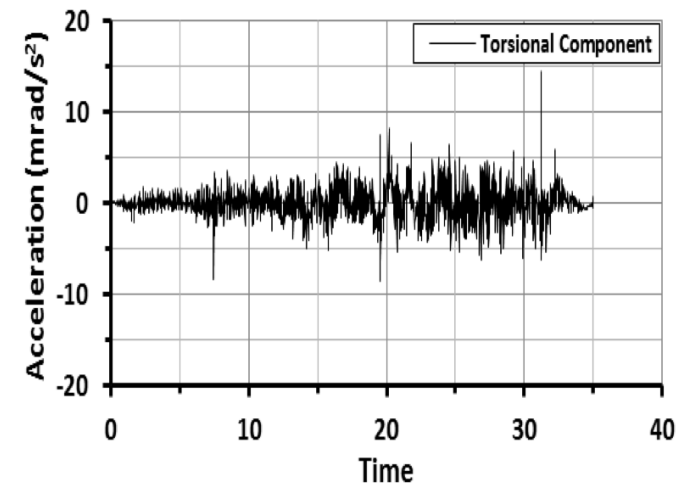

Tabas, Iran, 1978/09/16

Figure 3 (continued) (a) time history of rocking components, (b) time history of torsional components

\section{MODEL VERIFICATION}

To evaluate the verification of improved method, rotational components of San Fernando earthquake are obtained with this method and results are compared with results of (Lee and Liang, 2008). This earthquake is recorded on Feb 9, 1971 at Pacoima dam station where its horizontal $(\mathrm{S} 74 \mathrm{~W})$ and vertical components had a peak acceleration of 1055 and $696 \mathrm{~cm} / \mathrm{s}^{2}$, respectively. The peak values of rocking and torsional accelerations for shear wave velocity of $300 \mathrm{~m} / \mathrm{s}$ are calculated $-0.3725 \mathrm{rad} / \mathrm{s}^{2},-0.2480 \mathrm{rad} / \mathrm{s}^{2}$ by (Lee and Liang, 2008) and $-0.3833 \mathrm{rad} / \mathrm{s}^{2},-0.2545$ 
$\mathrm{rad} / \mathrm{s}^{2}$ by our research, respectively, which their differences are less than 3 percent. The rocking component time history at present work is also compared with (Lee and Liang, 2008) work in Figure 4 .
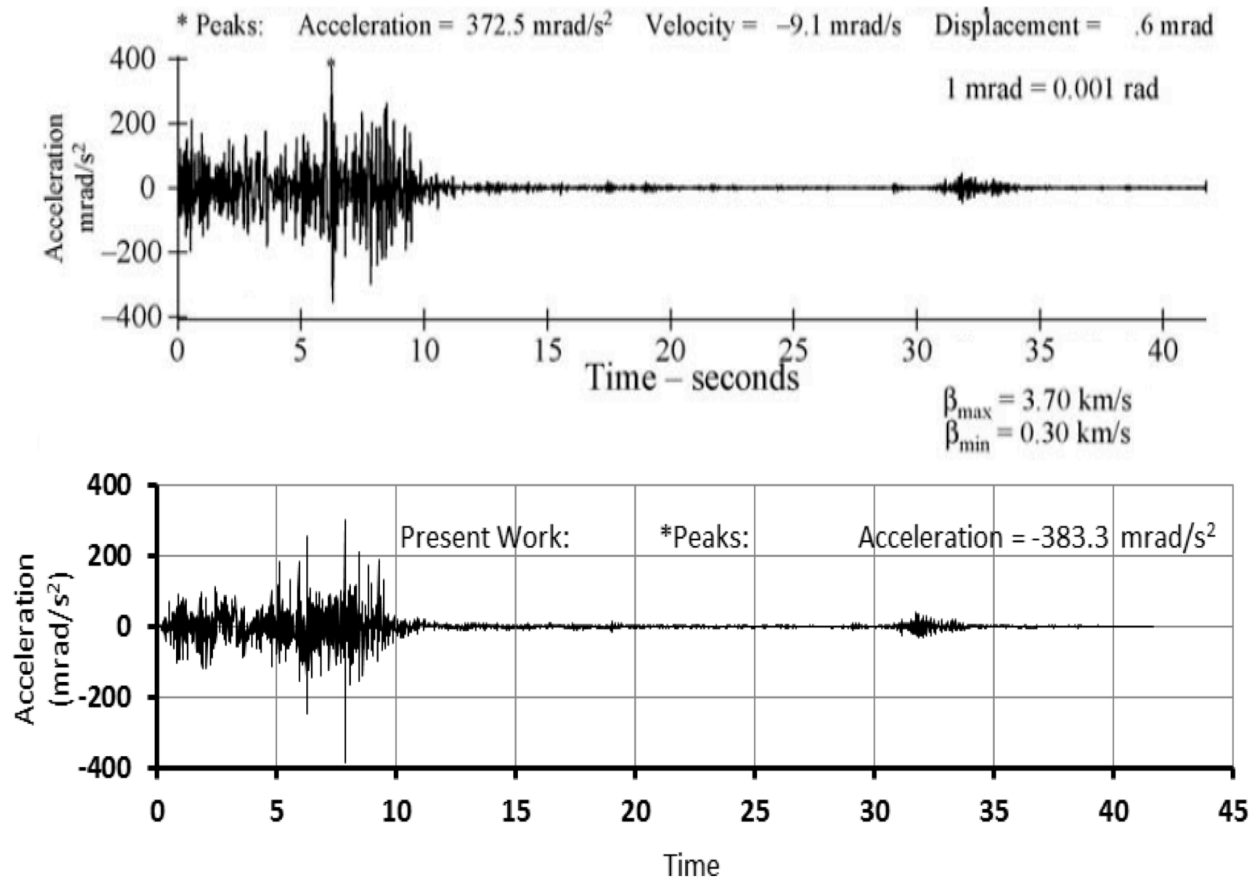

Figure 4 Rocking Component of San Fernando Earthquake (Lee and Liang, 2008) and obtained rocking component in this study

\section{SEISMIC RESPONSE OF ASSTS}

The modal analysis of ASSTs shows that the first two natural frequencies of empty tank are 3.4498 and 4.4332 Hertz, 3.5653 and 4.7810 Hertz for full tank and 3.4782 and 4.4791 Hertz for half tank. Linear analysis of these tanks are also carried out considering three translational and all six components of ground motion, separately and the results are summarized in Table 5 and 6 for empty tank and tank with water, respectively. In these Tables, variables $\left(\tilde{R}_{h}\right),\left(\tilde{U}_{)}\right.$and $\left(\tilde{R}_{v}\right)$ are denote the normalized structure responses where $\left(\tilde{R}_{h}\right)$ is the ratio of maximum base shear force for the model subjected to six components of ground motion to the same result obtained when the model is subjected to the three translational components. $(\tilde{U})$ and $\left(\tilde{R}_{v}\right)$ are ratios regarding the maximum horizontal displacement and vertical reaction force respectively. Normalized response larger than unity implies that the rotational components of the ground motion increase the tank's response and vice versa. 
Table 5 Results summary of linear dynamic analysis of empty ASSTs

\begin{tabular}{|c|c|c|c|c|c|c|c|}
\hline \multirow{2}{*}{ Earthquake } & \multirow{2}{*}{$\begin{array}{l}\text { Number of } \\
\text { Earthquake } \\
\text { Component }\end{array}$} & \multirow{2}{*}{$\begin{array}{c}\text { Max. } \\
\text { Base Shear } \\
\mathrm{R}_{\mathrm{h}}(\mathrm{kN})\end{array}$} & \multirow{2}{*}{$\begin{array}{c}\text { Max. } \\
\text { Horizontal } \\
\text { Displace- } \\
\text { ment } \\
\text { U (mm) }\end{array}$} & \multirow{2}{*}{$\begin{array}{c}\text { Max. } \\
\text { Vertical } \\
\text { Reaction } \\
\mathrm{R}_{\mathrm{v}}(\mathrm{kN})\end{array}$} & \multicolumn{3}{|c|}{$\begin{array}{c}\text { Normalized } \\
\text { response }\end{array}$} \\
\hline & & & & & $\left(\tilde{R}_{h}\right)$ & $(\tilde{U})$ & $\left(\tilde{R}_{v}\right)$ \\
\hline Chi-Chi & $3 \mathrm{C}$ & $2.930 \mathrm{E}+01$ & $1.870 \mathrm{E}-02$ & $3.277 \mathrm{E}+02$ & \multirow{2}{*}{0.999} & \multirow{2}{*}{0.999} & \multirow{2}{*}{1.000} \\
\hline Taiwan & $6 \mathrm{C}$ & $2.928 \mathrm{E}+01$ & $1.868 \mathrm{E}-02$ & $3.277 \mathrm{E}+02$ & & & \\
\hline \multirow{2}{*}{$\begin{array}{c}\text { Imperial } \\
\text { Valley }\end{array}$} & $3 \mathrm{C}$ & $3.074 \mathrm{E}+01$ & $2.037 \mathrm{E}-02$ & $3.134 \mathrm{E}+02$ & \multirow{2}{*}{1.434} & \multirow{2}{*}{1.836} & \multirow{2}{*}{1.000} \\
\hline & $6 \mathrm{C}$ & $4.409 \mathrm{E}+01$ & $3.741 \mathrm{E}-02$ & $3.134 \mathrm{E}+02$ & & & \\
\hline \multirow{2}{*}{$\begin{array}{c}\text { Kern } \\
\text { Country }\end{array}$} & $3 \mathrm{C}$ & $3.416 \mathrm{E}+01$ & $1.891 \mathrm{E}-02$ & $3.137 \mathrm{E}+02$ & \multirow{2}{*}{0.998} & \multirow{2}{*}{1.000} & \multirow{2}{*}{1.000} \\
\hline & $6 \mathrm{C}$ & $3.409 \mathrm{E}+01$ & $1.890 \mathrm{E}-02$ & $3.137 \mathrm{E}+02$ & & & \\
\hline \multirow{2}{*}{ Northridge } & $3 \mathrm{C}$ & $3.234 \mathrm{E}+01$ & $1.027 \mathrm{E}-02$ & $3.330 \mathrm{E}+02$ & \multirow{2}{*}{1.318} & \multirow{2}{*}{1.628} & \multirow{2}{*}{1.000} \\
\hline & $6 \mathrm{C}$ & $4.263 \mathrm{E}+01$ & $2.811 \mathrm{E}-02$ & $3.330 \mathrm{E}+02$ & & & \\
\hline \multirow{2}{*}{$\begin{array}{c}\text { San Fer- } \\
\text { nando }\end{array}$} & $3 \mathrm{C}$ & $4.047 \mathrm{E}+01$ & $1.881 \mathrm{E}-02$ & $3.328 \mathrm{E}+02$ & \multirow{2}{*}{0.990} & \multirow{2}{*}{0.986} & \multirow{2}{*}{1.000} \\
\hline & $6 \mathrm{C}$ & $4.007 \mathrm{E}+01$ & $1.855 \mathrm{E}-02$ & $3.328 \mathrm{E}+02$ & & & \\
\hline \multirow{2}{*}{ Tabas } & $3 \mathrm{C}$ & $3.658 \mathrm{E}+01$ & $1.951 \mathrm{E}-02$ & $3.328 \mathrm{E}+02$ & \multirow{2}{*}{1.025} & \multirow{2}{*}{1.024} & \multirow{2}{*}{1.000} \\
\hline & $6 \mathrm{C}$ & $3.748 \mathrm{E}+01$ & $1.997 \mathrm{E}-02$ & $3.328 \mathrm{E}+02$ & & & \\
\hline
\end{tabular}

For empty tank, it is remarkable that the maximum vertical reaction was not affected by the rotational components of ground motion. But the horizontal reaction and displacement can increase or decrease related to type of earthquakes. As shown in Table 5, rotational components of Imperial Valley earthquake have maximum effects on the response of empty tank. Time history of peak horizontal displacement and reaction force of empty tank due to Imperial Valley earthquake for the range of maximum variation is available are shown in Figure 5. As shown in this Figure, the effect of rotational components of ground motion on linear response of ASSTs cannot be negligible in some cases.

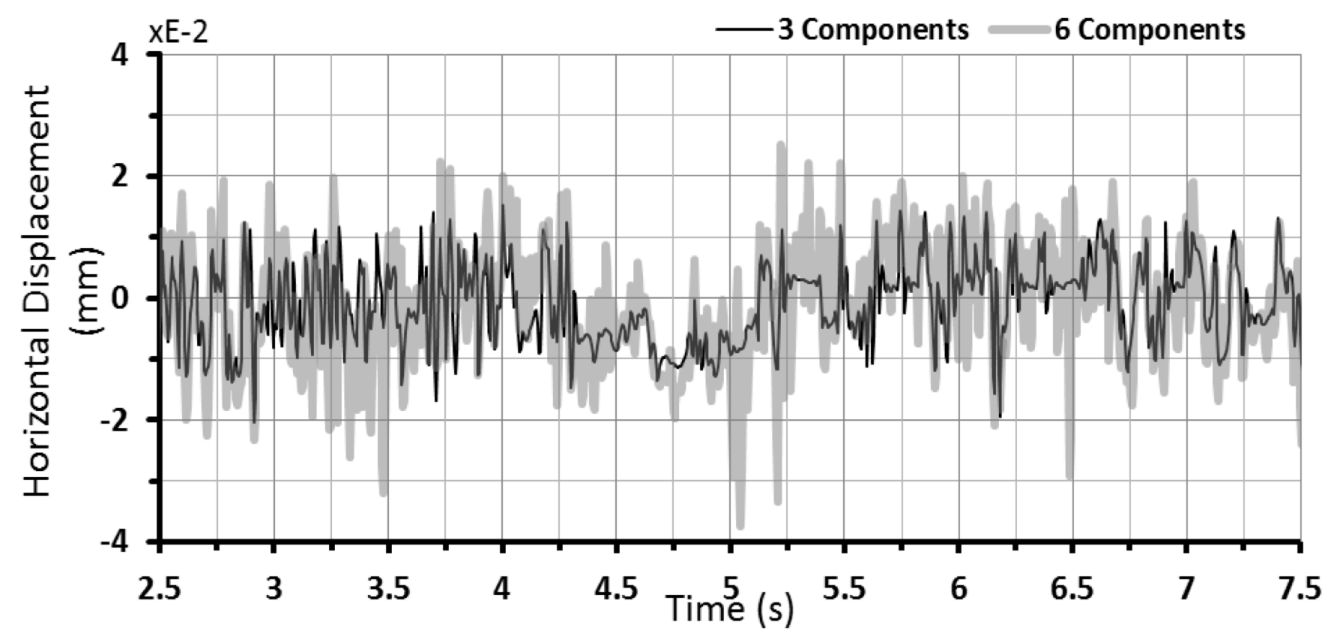

Figure 5 Linear response of empty tank for Imperial Valley earthquake 


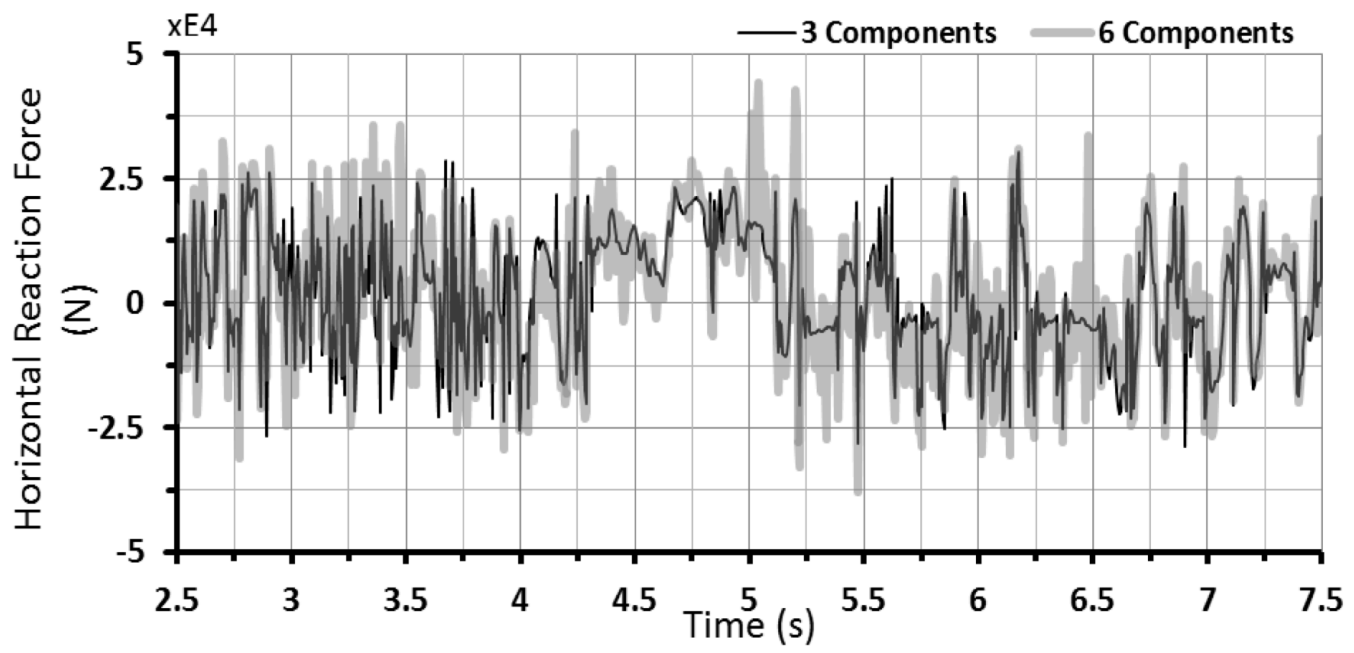

Figure 5 Linear response of empty tank for Imperial Valley earthquake

When the ASSTs are filled with water in different elevations and fluid-structure interaction is considered, the effect of rotational components of ground motion change the normalized responses. These results are presented in Table 6 for Imperial Valley earthquake and the time history of peak horizontal displacement and reaction force are shown in Figures 6 and 7 for half water and full water tanks respectively.

Table 6 Linear response of ASSTs with different water elevation for Imperial Valley earthquake

\begin{tabular}{|c|c|c|c|c|c|c|c|}
\hline \multirow{2}{*}{ Earthquake } & \multirow{2}{*}{$\begin{array}{l}\text { Number of } \\
\text { Earthquake } \\
\text { Component }\end{array}$} & \multirow{2}{*}{$\begin{array}{l}\text { Max. } \\
\text { Base Shear } \\
\mathrm{R}_{\mathrm{h}}(\mathrm{kN})\end{array}$} & \multirow{2}{*}{$\begin{array}{l}\text { Max. } \\
\text { Horizontal } \\
\text { Displace- } \\
\text { ment } \\
\text { U (mm) }\end{array}$} & \multirow{2}{*}{$\begin{array}{l}\text { Max. } \\
\text { Vertical } \\
\text { Reaction } \\
\mathrm{R}_{\mathrm{v}}(\mathrm{kN})\end{array}$} & \multicolumn{3}{|c|}{$\begin{array}{l}\text { Normalized } \\
\text { response }\end{array}$} \\
\hline & & & & & $\left(\tilde{R}_{h}\right)$ & $(\tilde{U})$ & $\left(\tilde{R}_{v}\right)$ \\
\hline \multirow{2}{*}{ Empty } & $3 \mathrm{C}$ & $3.074 \mathrm{E}+01$ & $2.037 \mathrm{E}-02$ & $3.134 \mathrm{E}+02$ & \multirow{2}{*}{1.434} & \multirow{2}{*}{1.836} & \multirow{2}{*}{1.000} \\
\hline & $6 \mathrm{C}$ & $4.409 \mathrm{E}+01$ & $3.741 \mathrm{E}-02$ & $3.134 \mathrm{E}+02$ & & & \\
\hline \multirow{2}{*}{ Half } & $3 \mathrm{C}$ & $8.392 \mathrm{E}+02$ & $1.122 \mathrm{E}-01$ & $3.075 \mathrm{E}+03$ & \multirow{2}{*}{1.000} & \multirow{2}{*}{1.092} & \multirow{2}{*}{1.000} \\
\hline & $6 \mathrm{C}$ & $8.392 \mathrm{E}+02$ & $1.125 \mathrm{E}-01$ & $3.075 \mathrm{E}+03$ & & & \\
\hline \multirow{2}{*}{ Full } & $3 \mathrm{C}$ & $1.617 \mathrm{E}+03$ & $5.285 \mathrm{E}-01$ & $6.833 \mathrm{E}+03$ & \multirow{2}{*}{1.000} & \multirow{2}{*}{0.986} & \multirow{2}{*}{1.000} \\
\hline & $6 \mathrm{C}$ & $1.617 \mathrm{E}+03$ & $5.213 \mathrm{E}-01$ & $6.833 \mathrm{E}+03$ & & & \\
\hline
\end{tabular}



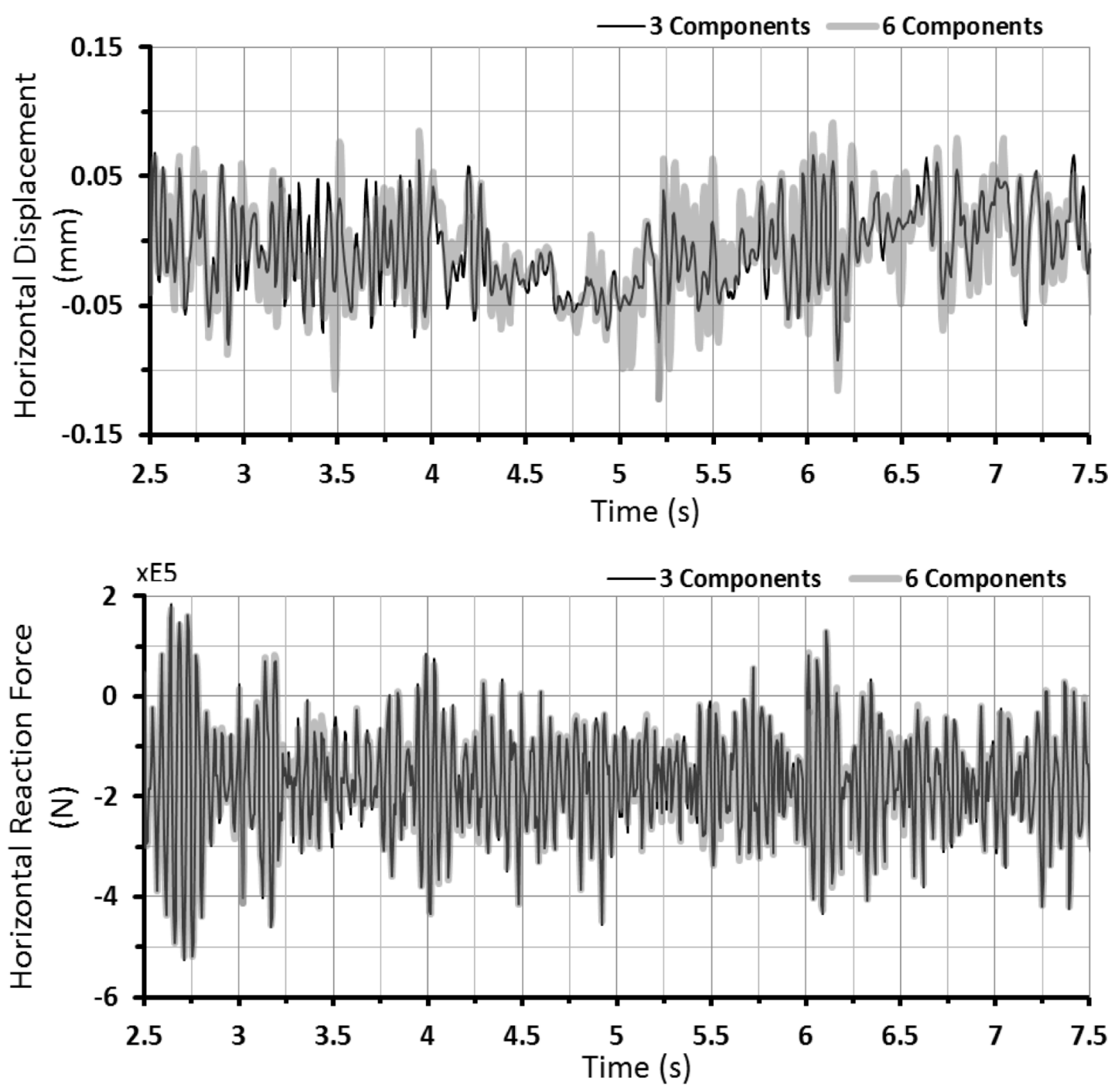

Figure 6 Linear response of half water storage tank for Imperial Valley earthquake 

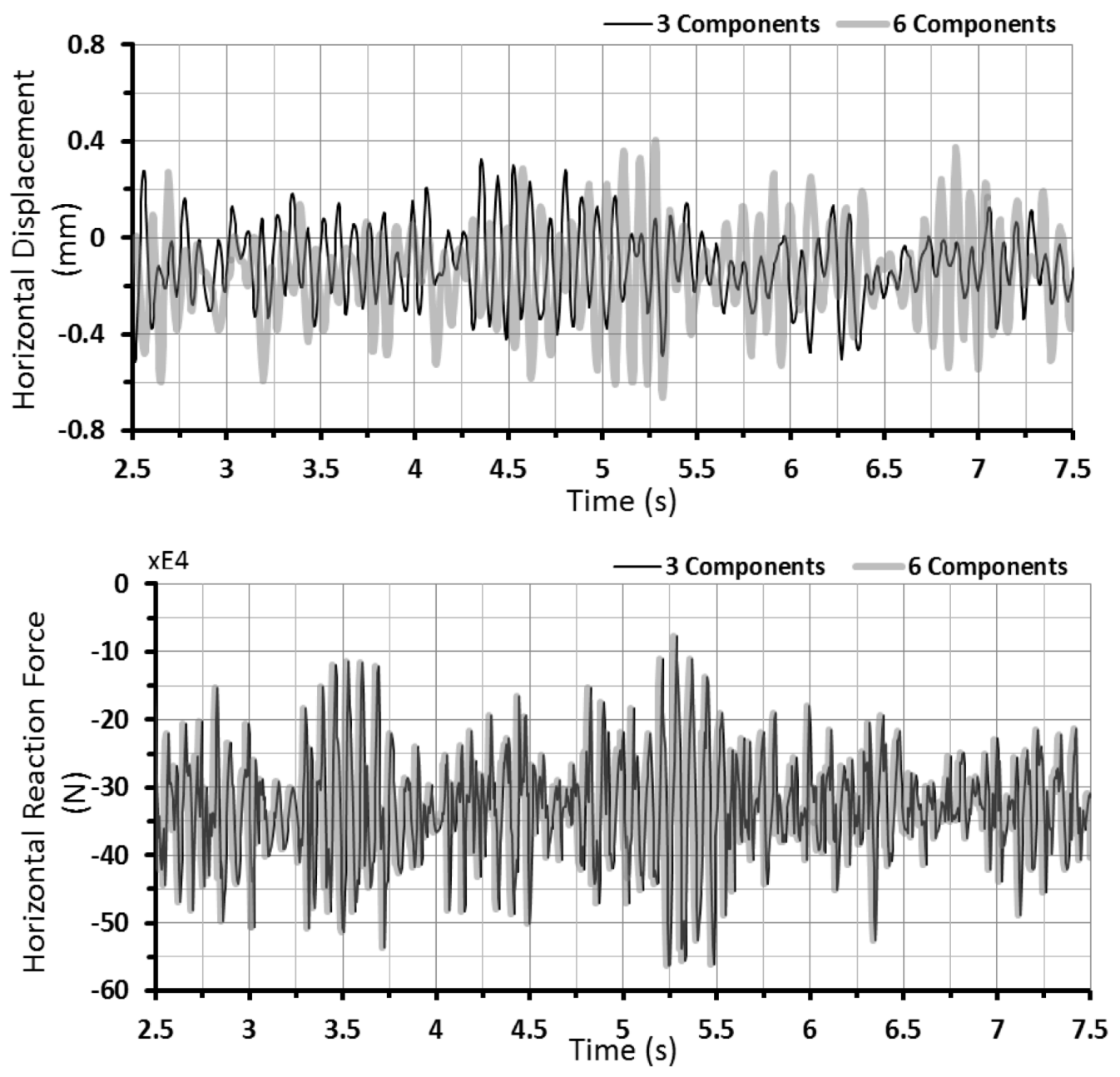

Figure 7 Linear response of full water storage tank for Imperial Valley earthquake

As shown in Tables 5 and 6 , it can be concluded that the rotational components of ground motion can decrease or increase some of the responses of structure depend on structure frequency and also frequency content of earthquake. As shown in Table 6, when the water elevation is increased, all responses of structure due to six components of ground motion near those due to three components and more increase of water elevation, results in lower responses due to six components of ground motion compared to three components.

\section{CONCLUSIONS}

In this paper, the effect of six correlated components of earthquake on linear dynamic responses of aboveground steel storage tanks (ASSTs) was investigated by finite element method. Furthermore the results were compared to ASSTs' responses of dynamic analysis under three correlated components of earthquake. Fluid-structure interaction based on Lagrangian-Lagrangian approach was considered. For this purpose only three translational components of accelerogram were avail- 
able, thus, three rotational components of the earthquake were obtained from translational components. The reliability of the method was confirmed by the reported data in the literature. Several types of ASSTs varying in fluid elevation with rigid foundations were modeled. As a result of the latter assumption, the soil-structure interaction was neglected. Linear dynamic analyses of these structures under six earthquakes (i.e. Chi-Chi Taiwan, Imperial Valley, Kern County, Northridge, San Fernando and Tabas Iran) with different type of site classification as well as various shear wave velocities in the range of $200 \mathrm{~m} / \mathrm{s}$ to $2000 \mathrm{~m} / \mathrm{s}$ revealed the following specific conclusions:

1. The response of ASSTs to six correlated components of ground motion could be increased or decreased, depending on the frequency content of the rotational components, their power amplitude, and the natural frequency of the structure.

2. With the same conditions between two earthquakes components (i.e. in equal peak ground acceleration (PGA) in vertical and horizontal direction) when seismic waves were propagated in the stiff soils, the shear wave velocity was higher than that occurred in the soft soils; hence, lower PGA was achieved in the rotational components compare to PGA of propagation in the soft soil. Therefore, the dynamic analysis response of ASSTs could be decreased in a stiff soil.

3. The rotational components of earthquake did not affect vertical reaction force in linear analysis; but they could alter the maximum base shear force and the maximum displacement.

4. The increase in the base shears and horizontal displacement of tank due to rotational excitations of ground motion are largest for empty aboveground tank.

5. The effect of rotational components was the most significant in tanks with less elevation of fluid; it may be due to similar variations of the natural frequencies and predominant frequency of their rotational components. As the elevation of fluid increased, the rotational stiffness of water storage tanks increased and the response of structures decreased.

6. In some cases in which the structure was laterally stiff and rotationally flexible, the rotational components of earthquake could increase the response of the structure. In contrary, inversed result could be obtained for rotationally stiff structures.

7. The analyses showed that structure responses could change by variation in peak acceleration, frequency content of earthquake and its rotational components, soil type, fluid elevation, and tank characteristics. So six-component earthquake analysis of structures such as ASSTs is necessary for design control. Also it leads to comprehensive understanding of seismic behavior of such special structures. 


\section{References}

Ahmadi, M. T. and Navayineya, B., 1995. Hydrodynamic Interaction Analysis of Dam Reservoir Using Lagrangian Approaches. (in Persian) Int. J. of Engineering, Iran, University of Science and Technology, Vol. 6, No.1-b.

Akkose, M., Adanur, S., Bayraktar, A. and Dumanoglu, A., 2008. Elasto-plastic earthquake response of arch dams including fluid-structure interaction by the Lagrangian approach., Applied Mathematical Modeling, No. 32, 2008, pp.2396-2412.

Attari, N. K, Rofooei, F. R., 2008. On lateral response of structures containing a cylindrical liquid tank under the effect of fluid-structure resonances. Journal of sound and vibration.

Awade, A. M., Humar, J. L., 1984. Dynamic response of buildings to ground motion. Can. J. Civil Eng. 11, 48-56.

Bielak, J., 1978. Dynamic response of building foundation system. Earthquake Eng. Dyn. 6, 17-30.

Castellani, A., Boffi, G., 1986. Rotational components of the surface ground motion during an earthquake. Earthquake Eng. Struct. Dyn. 14, 751-767.

Castellani, A., Boffi, G., 1989. On the rotational components of seismic motion. Earthquake Eng. Struct. Dyn. 18, 785-797.

Chopra, A. K., 2008. Dynamic of structures, Theory and application to earthquake engineering, 3rd Ed., Prentice Hall of India.

Datta, T. K., 2010. Seismic analysis of structures. John Wiley and Sons.

Ghafory-Ashtiany, M., Singh, M. P., 1986. Structural response for six correlated earthquake components. Earthquake Eng. and Struct. Dyn, 14, 103-119.

Ghayamghamian, M. R., Nouri, G. R., Igel, H. and Tobita, T., 2009. The effect of torsional ground motion on structural response: code recommendation for accidental eccentricity. Bulletin of the Seismological Society of America, Vol. 99, No. 2B, 1261-1270.

Goul, R. K., Chopra, A. K., 1994. Dual-level approach for seismic design of asymmetric-plan buildings. ASCE, J. Struct. Eng. 120, 161-179.

Latin American Journal of Solids and Structures 10(2013) 1155 - 1176 
Gupta, V. K., Trifunac, M. D., 1989. Investigation of buildings response to translational and rotational earthquake excitations. Report No. CE 89-02. Department of Civil Engineering, University of Southern California.

Hamdi, M. A., Ousset, Y., Verchery, G., 1978. A displacement method for the analysis of vibration of coupled fluid-structure system. Int. J. No.13.

Hong-Nan Li, Li-Ye Sun, Su-Yan Wang, 2004. Improved approach for obtaining rotational components of seismic motion. Nuclear Eng. and Design. 232, 131-137.

Housner, G. W., 1963. The dynamic behavior of water tanks. Bulletin of Seismological Society of America. 53, 381-387.

Kalani sarokolayi, L., Navayineya, B., Hosainalibegi, M., Vaseghi Amiri, J., 2008. Dynamic analysis of water tanks with interaction between fluid and structure. The 14th word conference on earthquake engineering, Beijing, China.

Kalani Sarokolayi, L., Navayi Neya, B., Tavakoli, H. R. 2012. Rotational Components Generation of Earthquake Ground Motion Using Translational Components, 15WCEE, Lisbon.

Kalkan, E., Graizer, V., 2007a. Coupled tilt and translational ground motion response spectra. J. struct. Eng. 133, No.5, 609-619.

Kalkan, E., Graizer, V., 2007b. Multi component ground motion response spectra for coupled horizontal, vertical, angular accelerations and tilt. ISET, J. Earthq. Technol. 44, No.1, 259-284.

Kana, D. D., Dodge, E.E., 1975. Design support modeling of liquid slosh in storage tanks subjected to seismic excitation. ASCE, 307-337.

Lee, V. W., 2007. Empirical scaling of strong motion response spectral amplitudes- a review. ISET, J. Earthq. Technol. 44, No.1, 39-69.

Lee, V. W., Trifunac, M. D., 1985. Torsional accelerograms. Soil Dyn. Earthquake Eng. 6, 75-89.

Lee, V. W., Trifunac, M. D., 1987. Rocking strong earthquake accelerations. Soil Dyn. Earthquake Eng. 6, 75-89.

Lee, V. W., Trifunac, M. D., 2009. Empirical scaling of rotational spectra of strong earthquake ground motion. Bull. Seismol. Soc. Am. 99, No.2B, 1378-1390. 
Moslem, M., Kianoush, M. R., Pogorzelski, W., 2011. Seismic response of liquid-filled elevated tanks. Journal of Eng. Struc. 33, 2074-2084.

Newmark, N. M., 1969. Torsion in symmetrical buildings. In: Proceeding of the 4th World Conference on Earthquake Engineering, 2, Santiago, Chile. PP. A3.19-A3.32.

Nouri, G. R., Ghayamghamian, M.R., Hashemifard, M., 2010. A comparison among different methods in the evaluation of torsional ground motion. Journal of Iran geophysics,4, 32-44.

Rericha, P., 2004 .Mohr-Coulomb failure condition and the direct shear test revisited. Acta Polytechnica, Vol.44, No. 5-6.

Takeo, M., 1998. Ground rotational motions recorded in near-source region of earthquakes. Geophys. Res. Lett. 25,789-792.

Trifunac, M. D., 1971. A method for synthesizing realistic strong ground motion, Bull. Seismol. Soc. AM. 61, No.6, 1730-1753.

Trifunac, M. D., 1976. Preliminary empirical model for scaling Fourier amplitude spectra of strong ground acceleration in terms of earthquake magnitude, source to station distance and recording site condition. Bull. Seismol. Soc. Am. 66, No.4, 1343-1373.

Trifunac, M. D., 1982. A note on rotational components of earthquake motions on ground surface for incident body waves. Soil Dyn. Earthquake Eng. 1, 11-19.

Latin American Journal of Solids and Structures 10(2013) $1155-1176$ 